\title{
DISSIPATIVE PROPERTIES OF NON-NEWTONIAN FLUID UNDER IMPACT LOAD
}

\author{
K. Jamroziak ${ }^{*}$, D. Pyka ${ }^{* *}$, J. Pach ${ }^{* * *}$, M. Bocian ${ }^{\dagger}$, A. Kurzawa ${ }^{\ddagger}$, J. Kurowski $^{\ddagger \ddagger}$
}

\begin{abstract}
The authors investigated the impact resistance of an energy absorber based on non-Newtonian fluid. To fabricate the material, polypropylene glycol and colloidal silica powder $14 \mu \mathrm{m}$ in diameter were used. Impact tests were conducted first on a gravity drop test and, after selecting proper mixture proportions, on an electromagnetic hammer. During the final research phase ballistic tests were conducted of composites the back layer of which consisted of shear thickening fluid enclosed in honeycomb shaped cells. The front layer of the composite consisted of aramid fabric in thermoplastic polymer matrix laminate. The composite was shot at with 9x19 mm Parabellum ammunition in order to assess dynamic deflection.
\end{abstract}

Keywords: energy dissipation, non-Newtonian fluid, impact loads, composites, ballistic tests

\section{Introduction}

One trend in research on construction materials is developing materials that absorb impact energy. Energy absorption is a significant enough factor to play the main role in construction criteria for applications where protection of human life and health is required. There are constantly tested new materials that could fulfill strict requirements for advanced safety systems. Among these materials are non-Newtonian fluids, which are objects of intensive research. This is confirmed by numerous publications (Pinto et al., 2017 and Wierzbicki et al., 2013). The properties of such materials can be a turning point not only for ballistics but in other industrial branches as well. Non-Newtonian fluids can be applied in flak jackets, sportswear, vehicle bumpers, or used for bridge construction. Wagner et al. initially applied the phenomenon of shear thickening fluid (STF) to the development of liquid body armor technology (Pacek et al., 2016 and Wagner et al., 2009). In current scientific research regarding ballistic applications of STF, they are mixed with aramid fabric (Gong et al., 2013; Kang et al., 2010 and Lomakin et al., 2011). As STF often used is a colloidal suspension of silica nanoparticles in an organic medium such as ethyl or polyethylene glycol. In this paper, colloid solutions of silica in propylene glycol were investigated. In the second stage of the research, composites of STF closed in honeycomb cells in laminate consisting of paraaramid fabric reinforcement of thermoplastic matrix were tested. The aim of the research was reduction of the dynamic deflection of the material system.

Assoc. Prof. Krzysztof Jamroziak, DSc., Eng.: Wroclaw University of Science and Technology, Faculty of Mechanical Engineering, Department of Mechanics, Materials Science and Engineering, Smoluchowskiego 25, Wroclaw 50-370, Poland, krzysztof.jamroziak@pwr.edu.pl

** $\quad$ MSc., Eng. Dariusz Pyka: Wroclaw University of Science and Technology, Faculty of Mechanical Engineering, Department of Mechanics, Materials Science and Engineering, Smoluchowskiego 25, Wroclaw 50-370, Poland, dariusz.pyka@pwr.edu.pl

*** Assis. Prof. Joanna Pach, DSc., Eng.: Wroclaw University of Science and Technology, Faculty of Mechanical Engineering, Department of Foundry, Plastics and Automation, Łukasiewicza 5, 50-370 Wroclaw, Poland, joanna.pach@pwr.edu.pl

† Assis. Prof. Mirosław Bocian, DSc., Eng.: Wroclaw University of Science and Technology, Faculty of Mechanical Engineering, Department of Mechanics, Materials Science and Engineering, Smoluchowskiego 25, Wroclaw 50-370, Poland, miroslaw.bocian@pwr.edu.pl

‡ Assis. Prof. Adam Kurzawa, DSc., Eng.: Wroclaw University of Science and Technology, Faculty of Mechanical Engineering, Department of Foundry, Plastics and Automation, Smoluchowskiego 25, Wroclaw 50-370, Poland, adam.kurzawa@pwr.edu.pl

抹 MSc., Eng. Janusz Kurowski: The company IM/kompozyty, Topolowa 5, Stanowice 55-200, Poland, office@kompozyty.pl 


\section{Methods}

Research on energy absorption of non-Newtonian fluids was conducted in three phases. The first phase aimed to select the most favorable percentage ratio of silica to the glycol. The research was conducted on a gravity drop test, with an impact energy of $60 \mathrm{~J}$. Residual energy and deformation were measured. The second phase of the research was defining the energy absorption of the selected solution under different initial speeds and assessing the proportions when shear thickening fluid is obtained. During the third phase, ballistic resistance research was conducted on the composite of STF in para-aramid fabric.

\subsection{Impact testing}

Initial drop test research was conducted on samples of respectively 20, 25 and $30 \%$ of the volumetric rate of silica to glycol. The maximal speed of the hammer was $4.5 \mathrm{~m} / \mathrm{s}$. The obtained results are shown in Fig. 1.

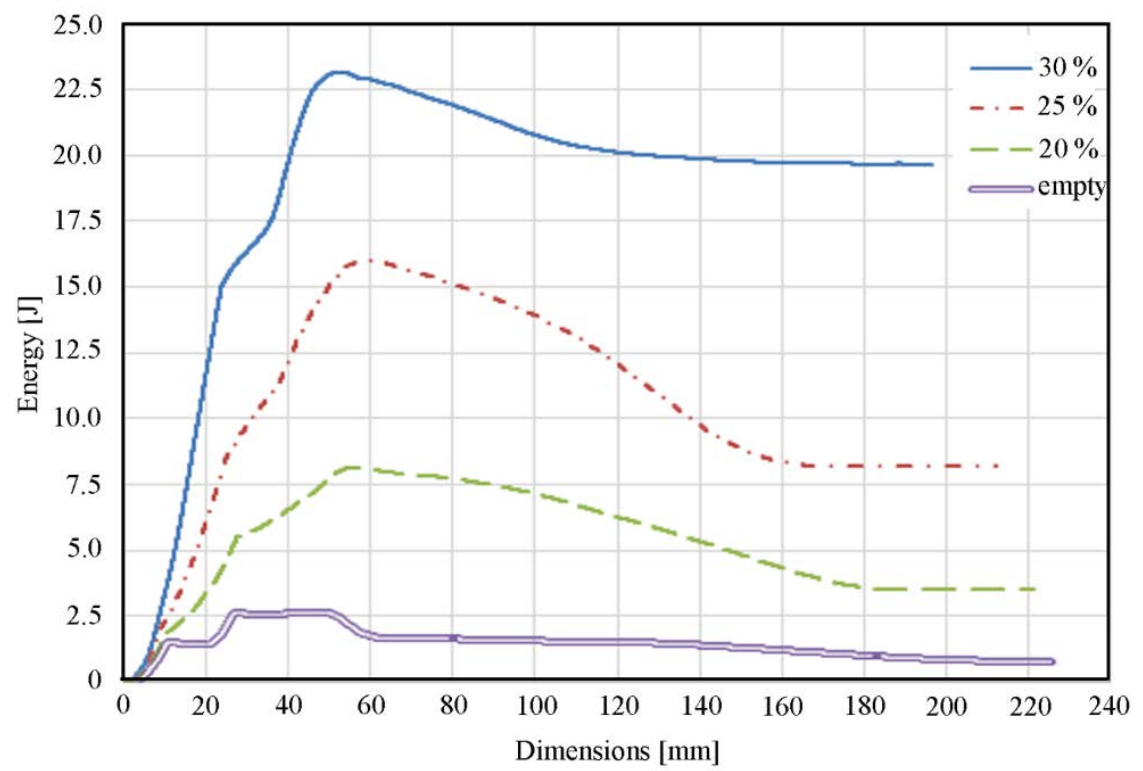

Fig. 1: Results obtained in gravity drop test.

The material with a colloid of $30 \%$ sillica to glycol volumetric rate had the highest energy adsorption. The first peak in case of all materials is caused by polymeric layer damage under which the liquid was contained.

During further research, colloidal sillica solutions in propylene glycol of different proportions were tested, the liquid was closed in honeycomb cells of $12 \mathrm{~mm}$ thickness, laminated with polymeric foil. There were determinate force-time characteristics for different speed ranges. In order to achieve that, an electromagnetic hammer was used, which allowed the penetrator speed to be adjusted by changing the initial voltage. Selected series of the samples was investigated for five different speed ranges that were initiated by respectively 20,30, 40, 50 and $60 \mathrm{~V}$. The displacement was measured using an encoder and read using an ADIDATA measurement port (Fig. 2). The gained impact force was measured using a force sensor located on the penetrator. The obtained results are showed in Tab.1.

Tab. 1: Impact speeds.

\begin{tabular}{ccccc}
\hline No. & $\begin{array}{c}\text { Initial voltage } \\
{[\mathrm{V}]}\end{array}$ & $\begin{array}{c}\text { Initial speed } \\
{[\mathrm{m} / \mathrm{s}]}\end{array}$ & $\begin{array}{c}\text { Impact force } \\
{[\mathrm{N}]}\end{array}$ & $\begin{array}{c}\text { Deformation } \\
{[\mathrm{mm}]}\end{array}$ \\
\hline 1 & 20 & 2.9 & 23.3 & 15.0 \\
\hline 2 & 30 & 3.6 & 32.5 & 21.2 \\
\hline 3 & 40 & 3.5 & 32.6 & 21.0 \\
\hline 4 & 50 & 3.4 & 28.7 & 21.1 \\
\hline 5 & 60 & 3.3 & 27.0 & 18.0 \\
\hline
\end{tabular}




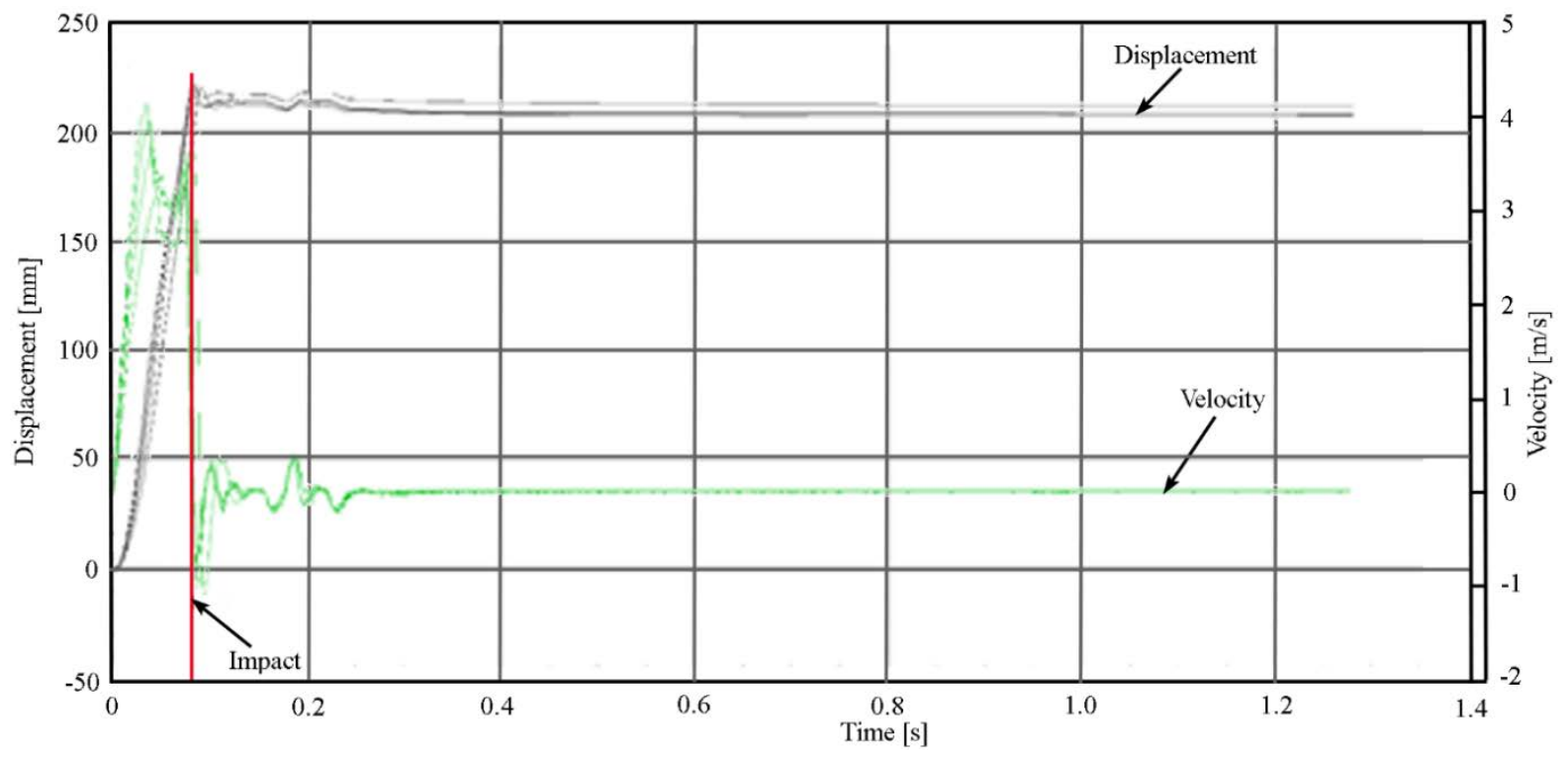

Fig. 2: Results for 5 speeds gained on an electromagnetic hammer and the displacement.

The signal acquisition and control of the test parameters of the harvesting device, the rectifier AC/DC, a microprocessor and a base station were provided by a dedicated system named PicoPower Platform, based on a system by Heron Hunt Engineering UK. In Fig. 3 the work of the hammer from the start with marked moment of the impact is shown.

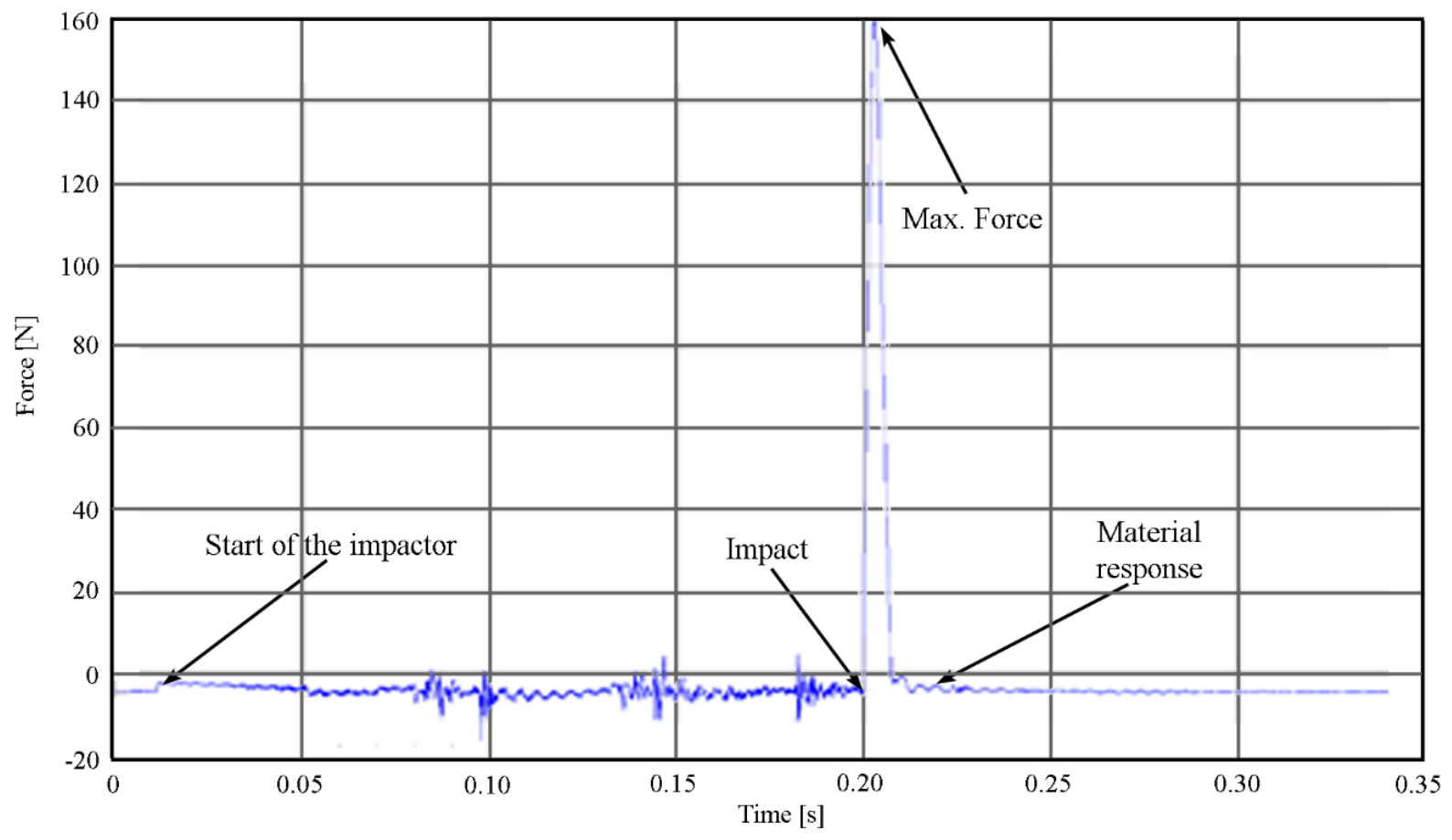

Fig. 3: Force signal on the sensor.

\subsection{Ballistic tests}

Research on the ballistic resistance of the composite was conducted on 5 sample series: $12 \mathrm{~mm}$ thick honeycomb cell undercoat and $4.4 \mathrm{~mm}$ para-aramid layer. Each sample was shot once using 9x19 mm Parabellum pistol bullets with a mean initial speed $353 \mathrm{~m} / \mathrm{s}$. Velocities were measured by Doppler radar, type Weibel SL-525PE, in accordance with U.S. Department of Justice NIJ Standard-0101.06. (NIJ, 2008). The dynamic deflection was measured with back face signature (BFS) using ballistic plasticine. An example of the shooting results is shown in the Fig. 4. 

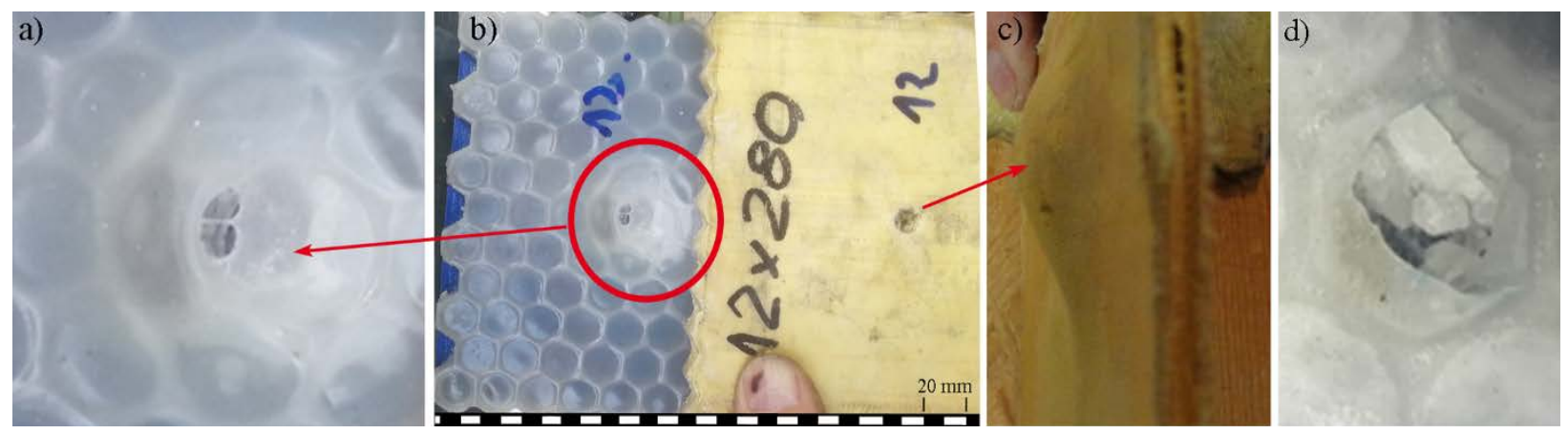

Fig. 4: Images of damaged composite: a) macroscopic image of the cell with non-Newtonian fluid, b) damaged composite: left side - honeycomb cells, right side - para-aramid layer, c) the back side of the para-aramid sample with characteristic constant deflection cone, $d$ ) powder elements of damaged honeycomb cells.

As is visible in Fig. 4b, the material damage is located also in neighboring cells. That indicates the nonlocal character of the projectile behavior. The mean area of the honeycomb structure damage was 3600 $\mathrm{mm}^{2}$. The dynamic deflection was around $24 \mathrm{~mm}$. The face-layering of the central cell was breached and became powder-like (Fig. 4a, 4d). All projectiles were stopped, which is confirmed by impact cone occurrence (Fig. 4c).

\section{Conclusions}

The main focus of this paper was to develop a composite which would use the shear thickening fluid phenomenon. The ballistic resistance of a colloidal solution of silica in polypropylene glycol, closed in honeycomb cells, was tested. An additional layer of the composite was laminate composed of para-aramid fabric reinforcement in a thermoplastic matrix of a specific weight of $280 \mathrm{~g} / \mathrm{cm}^{2}$. The research target, which was reduction of dynamic deflection, was achieved. In the analyzed case, the deflection was 24 $\mathrm{mm}$, where in previous research it varied between 32 and $38 \mathrm{~mm}$ under fire with the same ammunition. Minimization of the BFS range is an important parameter when assessing behind armor blunt trauma (BABT). Further research will be conducted by the authors on the model of the Hybrid III dummy.

\section{References}

Gong, X., Xu Y., Zhu, W., Xuan, S. and Jiang, W. (2013) Study of the knife stab and puncture-resistant performance for shear thickening fluid enhanced fabric. Journal of Composite Materials, 20, pp. 1-17.

Kang, T.J., Hong, K.H. and Yoo, M.R. (2010) Preparation and properties of fumed silica/Kevlar composite fabrics for applications of stab resistant material, Fibers and Polymers, 11, 5, pp. 719-724.

Lomakin, E.V., Mossakovsky, P.A., Bragov, A.M., Lomunov, A.K., Konstantinov, A.Yu., Kolotnikov, M.E., Antonov, F.K. and Vakshtein M.S. (2011) Investigation of impact resistance of multilayered woven composite barrier impregnated with the shear thickening fluid. Archive of Applied Mechanics, 81, 12, pp. 2007-2020.

NIJ Standard-0101.06, Ballistic Resistance of Body Armor. U.S. Department of Justice, July 2008.

Pacek, D., Zochowski, P. and Wisniewski, A. (2016) Anti-trauma pads based on non-Newtonian materials for flexible bulletproof inserts, in: Proc. 29th International Symposium on Ballistics, Edinburgh, Scotland, pp. 20342045.

Pinto, F. and Meo, M. (2017) Design and manufacturing of a novel shear thickening fluid composite (STFC) with enhanced out-of-plane properties and damage suppression. Applied Composite Materials, 24, 3, pp 643-66.

Wagner, N. and Wetzel, ED. (2009) Advanced body armor utilizing shear thickening fluids. Patent 7498276, USA.

Wierzbicki, L., Danelska, A., Olszewska, K., Tryznowski, M., Zielinska, D., Kucinska, I., Szafran, M. and Leonowicz, M. (2013) Shear thickening fluids based on nanosized silica suspensions for advanced body armour. Composites Theory and Practice, 13, 4, pp. 241-244. 